\title{
ORIENTAÇÃO PROFISSIONAL, GAMIFICAÇÃO E EDUCAÇÃO PROFISSIONAL E TECNOLÓGICA: UMA REVISÃO SISTEMÁTICA DE LITERATURA
}

\author{
Yane Ferreira Machado ${ }^{1}$ \\ Francisco Kelsen de Oliveira ${ }^{2}$
}

\section{RESUMO}

Tendo em vista a mudança comportamental dos estudantes nas novas gerações, considerando a popularização da tecnologia, entende-se que a Orientação Profissional (OP) precisa ater-se a essas transformações. Desse modo, a gamificação aparece como uma possibilidade de trabalho, inclusive no campo da Educação Profissional e Tecnológica (EPT). Diante desse cenário, o presente trabalho objetiva verificar as possíveis aproximações entre a OP, a gamificação e a EPT. Para tanto, parte-se de uma Revisão Sistemática de Literatura. A partir das pesquisas é possível inferir que a gamificação é um tema que vem ganhando espaço atualmente, uma característica não tão presente na Orientação Profissional, não tendo sido encontrados resultados relacionando esses dois eixos na literatura pesquisada. Todavia, isso não implica na rejeição da proposta de combinar a gamificação com a orientação profissional, ao contrário disso, reforça a ideia de que a estratégia de gamificação, que já está sendo utilizada em vários contextos conforme a RSL pode promover o engajamento dos participantes e abre ainda mais questionamentos que carecem de investigação teórica e experimentação prática que possam comprovar ou refutar a viabilidade de combinar no processo de Orientação Profissional as estratégias de gamificação e direcioná-la para estudantes da Educação Profissional e Tecnológica.

Palavras-chave: Educação Profissional e Tecnológica; Orientação Profissional; Gamificação; Revisão sistemática de literatura.

\section{PROFESSIONAL ORIENTATION, GAMING AND PROFESSIONAL AND TECHNOLOGICAL EDUCATION: A SYSTEMATIC REVIEW OF LITERATURE}

\begin{abstract}
In view of the behavioral change of the students in the new generations, considering the popularization of technology, it is understood that the Professional Orientation (OP) must keep up with these transformations. In this way, gamification appears as a possibility of work, including in the field of Professional and Technological Education (EPT). Given this scenario, the present work aims to verify the possible approximations between PB, gamification and EPT. To do so, we start with a Systematic Review of Literature. From the researches it is possible to infer that gamification is a topic that is

\footnotetext{
${ }^{1}$ Discente do Mestrado Profissional em Educação Profissional e Tecnológica - ProfEPT do Instituto Federal de Educação, Ciência e Tecnologia - IF Sertão/Campus Salgueiro. E-mail: yaneferreirapsi@gmail.com

2 Professor doutor do Mestrado Profissional em Educação Profissional e Tecnológica - ProfEPT do Instituto Federal de Educação, Ciência e Tecnologia - IF Sertão/Campus Salgueiro. E-mail: francisco.oliveira@ifsertao-pe.edu.br
} 
gaining space today, a characteristic not so present in the Professional Orientation, and no results were found relating these two axes in the researched literature. However, this does not imply rejection of the proposal of combining gamification with professional guidance, rather it reinforces the idea that the gamification strategy, which is already being used in various contexts according to RSL, can promote the engagement of the participants and opens up even more questions that require theoretical investigation and practical experimentation that can prove or refute the feasibility of combining in the Professional Orientation process the strategies of gamification and direct it to students of Professional and Technological Education.

Keywords: Professional and technological education; Professional guidance; Gamification; Systematic review of literature.

\section{INTRODUÇÃO}

Este trabalho tem como cerne a Orientação Profissional (OP) na Educação Profissional e Tecnológica (EPT) combinada às chamadas Metodologias Ativas, nesse caso em específico, a estratégia de Gamificação.

Assim, a questão central a ser analisada é a possibilidade de desenvolvimento de um modelo de Orientação Profissional entre os estudantes da Educação Profissional e Tecnológica a partir de estratégias de Gamificação. Essa inquietação surge a partir da mudança no perfil comportamental dos estudantes nas novas gerações. Bastante influenciada pela popularização da tecnologia, a geração de nativos digitais traz um funcionamento marcado pela fluidez, menor apego aos padrões pré-estabelecidos e rapidez nas mudanças.

Outrossim, a Orientação Profissional, enquanto metodologia de trabalho dos profissionais da Educação e da Psicologia, precisa ater-se a estas mudanças e buscar o desenvolvimento de pesquisas que permitam acompanhá-las, tendo em vista que estas estão ocorrendo e, diante disso, essas ciências não podem se manter alheias (MACHADO; OLIVEIRA, 2018).

Outra questão a ser considerada são as formas híbridas de trabalho e os vínculos empregatícios frágeis e precarizados (ANTUNES, 2009). Esse é outro aspecto que também afeta a Orientação Profissional em uma perspectiva mais ampla. Se antes a OP era pensada como um processo diretivo, que iria apontar a profissão certa para o jovem vestibulando, hoje é necessário uma visão mais ampla, considerando não só a escolha, mas o processo de desenvolvimento de carreira, o reconhecimento do profissional nas 
atividades que realiza em seu trabalho, a reorientação e a recolocação profissional. Em suma, temos um processo que pode ser desenvolvido ao longo da vida laboral dos sujeitos, isso em uma perspectiva desenvolvimentista, indo desde a adolescência até a aposentadoria (MUNHOZ; MELO-SILVA; AUDIBERT, 2016).

Assim, é importante atentar para o fato que novos arranjos no mundo do trabalho trazem repercussões que afetam a OP e a EPT em seus desenhos, dinâmicas e estruturas. Não se trata de uma subsunção aos ideais capitalistas de "formar para o mercado de trabalho", mas sim contribuir para a formação humana, apesar dos apelos mercadológicos de consumo à massa trabalhadora.

Nesse sentido, esse trabalho procura investigar, a partir da Revisão Sistemática de Literatura (RSL), possíveis aproximações ou não, entre Orientação Profissional, Gamificação e Educação Profissional e Tecnológica e no intuito de esclarecer esses principais conceitos que dão origem a este trabalho, passaremos a explaná-los a seguir, ainda de forma sintética.

A Orientação Profissional (O.P) pode ser compreendida como um processo que visa facilitar o processo de decisão, amadurecimento e desenvolvimento da escolha profissional do sujeito. Santos, Luna e Bardagi (2012), percebem o desenvolvimento da O.P perpassando a realidade histórica e social em que o sujeito/orientando vive, compreendendo um momento de ampliação da sua consciência que transcorre pelo autoconhecimento, questões relacionadas ao mundo do trabalho e às áreas ou cursos de interesse do orientando.

Tradicionalmente, os processos de O.P tem sido desenvolvidos vinculados às áreas da psicologia e educação, e conta com combinações de instrumentos e métodos com enfoque quantitativo e qualitativo (AMBIEL et al., 2017), sem no entanto, esgotar a discussão sobre qual enfoque é o mais eficaz e capaz de auxiliar os sujeitos, sobretudo no processo de escolha profissional. Dito isto, passamos a explorar a perspectiva da gamificação.

O entendimento de gamificação adotado neste trabalho baseia-se nas ideias de Jorge e Sutton (2016) quando estes apontam que o estabelecimento de desafios, regras, interação, feedbacks e outros estímulos que geram respostas emocionais de envolvimento nos participantes/jogadores "é uma estratégia holística, capaz de engajar os indivíduos" (JORGE; SUTTON, 2016, p. 104) e isso pode ocorrer em diferentes 
contextos, como organizações e instituições educativas, por exemplo. Em linhas gerais gamificar significa trazer elementos de jogos como os elencados acima, para contextos que não são de jogos naturalmente, mas que através dessa estratégia podem se tornar mais envolventes e manter as pessoas engajadas nas tarefas propostas.

Para Massi (2017), a gamificação permite inovar as metodologias de ensino “criando espaços de aprendizagem mediados pelo desafio, pelo prazer e entretenimento, proporcionando graus de imersão e diversão que dificilmente são atingidos pelos métodos tradicionais" (MASSI, 2017, p. 20). Esse tipo de intervenção permite que o sujeito interaja e se relacione de forma ativa com o que se espera que ele aprenda. No caso do seu uso na orientação profissional, esse ambiente lúdico seria utilizado para criar, por exemplo, um momento de vivência experimental ou um espaço de simulação em que o estudante poderá experimentar desenvolver papéis profissionais em um ambiente controlado (MACHADO; OLIVEIRA, 2018).

A ideia de explorar a utilização desses recursos na Educação Profissional e Tecnológica (EPT) deve-se justamente ao fato de que essa perspectiva educacional tem como objetivo formar pessoas com autonomia e que sejam capazes de se posicionar e intervir baseadas na ética e na relevância social diante das relações complexas que se desenvolvem no mundo do trabalho (VIEIRA; VIEIRA, 2016).

Essa modalidade de educação é colocada por Ramos (2014) como uma possibilidade de transição na direção formativa pretendida para os jovens brasileiros, pois ainda de acordo com a autora, a realidade socioeconômica brasileira exige um tipo de ensino médio fundamentado na concepção de formação humana integral, estruturado sobre os eixos: trabalho, ciência, tecnologia e cultura. Assim, fica evidenciado que a proposta da EPT não compreende uma formação voltada para a profissionalização em prol do mercado, mas uma formação ampla, omnilateral, capaz de transformar a realidade dos sujeitos que dela participam.

Da união dessas três perspectivas, temos o início da investigação acerca da viabilidade de desenvolver junto aos estudantes da EPT, processos de orientação profissional aliados a elementos da gamificação, uma vez que acredita-se que esse público é composto por um grande número de jovens nascidos e educados dentro de um contexto social atravessado pelas Tecnologias Digitais de Informação e Comunicação (TDIC's). Como forma de iniciar a exploração dessa temática, temos o presente 
trabalho, que tem o intuito de mapear preliminarmente esses conceitos. A seguir será exposto o protocolo de RSL e as características da pesquisa realizada.

\section{PERCURSO METODOLÓGICO}

Esse trabalho foi desenvolvido a partir de uma Revisão Sistemática de Literatura (RSL) usando motor de busca na WEB na plataforma do Google Scholar a partir da combinação de palavras-chave (strings). Trata-se de uma pesquisa de abordagem qualitativa e enfoque exploratório, com o objetivo de fazer um reconhecimento dos materiais publicados sobre orientação Profissional, Gamificação e Educação Profissional e Tecnológica, nos últimos cinco anos. A coleta do material foi sistematizada através de um protocolo de RSL os principais tópicos estão expostos a seguir.

\section{Seleção dos estudos, fontes de busca e palavras-chave}

Para esse levantamento buscou-se estudos que apresentassem modelos ou experiências de uso da gamificação e de orientação profissional, conceituação de Educação Profissional e Tecnológica na plataforma do Google Scholar publicados entre janeiro de 2014 e outubro de 2018 e disponíveis para download gratuitamente. A escolha por esse recorte temporal deu-se em virtude da mutabilidade acerca do uso das tecnologias, tornando trabalhos com mais de cinco anos de publicação em alguns casos descontextualizados ou obsoletos. Ademais, optou-se pela plataforma do Google Scholar como uma forma de conduzir uma exploração inicial sobre o tema da pesquisa, com o intuito futuro de expandir para outras plataformas como Scielo, portal de periódicos da CAPES e ScienceDirect em pesquisas futuras.

O recorte de abrangência incorporou estudos primários e secundários, nos quais estavam contidos estudos exploratórios, estudos de caso, relatos de experiência, experiência de uso e revisões sistemáticas de literatura/mapeamento sistemático/revisão integrativa de literatura sobre os temas da pesquisa.

Como procedimento para seleção dos estudos foram estabelecidas três etapas, sendo inicialmente utilizados os strings de busca na fonte de pesquisa selecionada, neste caso o Google Scholar. As expressões utilizadas encontram-se expostas no Quadro 1: 
Quadro 1 - Strings de busca e seus resultados

\begin{tabular}{|c|c|c|c|c|c|}
\hline ID & String de busca & $\begin{array}{c}\mathrm{N}^{\mathbf{0}} \text { de } \\
\text { trabalhos } \\
\text { encontrados } \\
\text { na } \\
\text { plataforma } \\
\text { Google } \\
\text { acadêmico }\end{array}$ & $\begin{array}{c}\mathbf{N}^{\mathbf{0}} \\
\text { trabalhos } \\
\text { selecionados } \\
\text { para análise }\end{array}$ & \begin{tabular}{l}
\multicolumn{1}{c}{$\mathrm{N}^{\circ}$ de } \\
trabalhos \\
incluídos
\end{tabular} & $\begin{array}{c}\mathrm{N}^{\mathrm{o}} \text { de } \\
\text { trabalhos } \\
\text { excluídos }\end{array}$ \\
\hline S1 & $\begin{array}{l}\text { "revisão sistemática } \\
\text { de literatura" + } \\
\text { "orientação } \\
\text { profissional" }\end{array}$ & 50 & 4 & 1 & 3 \\
\hline S2 & $\begin{array}{l}\text { "revisão sistemática } \\
\text { de literatura" + } \\
\text { "gamificação" }\end{array}$ & 53 & 25 & 12 & 13 \\
\hline S3 & $\begin{array}{l}\text { "revisão sistemática } \\
\text { de literatura" + } \\
\text { "educação } \\
\text { profissional } \\
\text { tecnológica" }\end{array}$ & 20 & 7 & 0 & 7 \\
\hline Total & & 123 & 36 & 13 & 23 \\
\hline
\end{tabular}

Fonte: Fonte: a autora, adaptado de Oliveira e Gomes (2015)

$\mathrm{Na}$ busca, utilizando as expressões "revisão sistemática de literatura" + “orientação profissional”, foram encontrados 50 trabalhos, sendo selecionados 4 para a leitura completa e incluído apenas 1 dos estudos. Ao usarmos a string de busca "revisão sistemática de literatura" + "gamificação" foram encontrados 53 resultados, dos quais 25 foram selecionados para uma análise mais detalhada, dos quais 12 foram selecionados. Já na busca com o termo "revisão sistemática de literatura" + "educação profissional e tecnológica" foram apresentados 20 resultados, dos quais 7 estudos foram coletados para análise mais detalhada. Contudo, nenhum deles atendeu ao critério de apresentar definições sobre Educação Profissional e Tecnológica.

$\mathrm{Na}$ segunda etapa foi feita a primeira leitura do título, palavras-chaves, resumo (contexto-motivação/problema e objetivo) e conclusão/considerações finais e avaliados de acordo com os critérios de inclusão e exclusão, para então selecionar uma lista inicial de fontes de estudos.

$\mathrm{Na}$ terceira etapa foi realizada uma segunda leitura, desta vez do estudo completo para extração das informações e realizado o fichamento dos textos selecionados. Os estudos foram avaliados quanto a sua qualidade em relação ao que se almeja nesta pesquisa, observando se estes apresentavam definições e/ou modelos de processos de 
Orientação Profissional, experiências de uso de Gamificação e conceituação de Educação Profissional e Tecnológica. Os critérios de inclusão e exclusão estão dispostos no Quadro 2:

Quadro 2 - Critérios de inclusão ou exclusão de materiais para as etapas 2 e 3 da RSL

\begin{tabular}{|c|c|c|}
\hline Critérios & ID & Descrição \\
\hline \multirow{5}{*}{ Inclusão } & I1 & $\begin{array}{l}\text { Artigos completos ou resumidos publicados em } \\
\text { periódicos científicos da base de dados }\end{array}$ \\
\hline & $\mathrm{I} 2$ & $\begin{array}{l}\text { Artigos completos ou resumo expandido que } \\
\text { apresentem conceituação e modelos de processos } \\
\text { de Orientação Profissional }\end{array}$ \\
\hline & I3 & $\begin{array}{l}\text { Artigos completos ou resumo expandido que } \\
\text { apresentem experiências de uso de gamificação }\end{array}$ \\
\hline & I4 & $\begin{array}{l}\text { Artigos completos ou resumo expandido que } \\
\text { apresentem a conceituação de Educação } \\
\text { Profissional e Tecnológica. }\end{array}$ \\
\hline & I5 & $\begin{array}{l}\text { Publicação de janeiro de } 2014 \text { a outubro de } 2018 \\
\text { PQ? }\end{array}$ \\
\hline \multirow{7}{*}{ Exclusão } & E1 & $\begin{array}{l}\text { Artigos não relevantes para a pesquisa (excluídos } \\
\text { pelo título, resumo e palavras-chave que não se } \\
\text { relacionam aos objetivos desta RSL) }\end{array}$ \\
\hline & E2 & Teses e dissertações \\
\hline & E3 & Artigos não disponíveis para download \\
\hline & E4 & Artigos disponíveis em outros idiomas \\
\hline & E5 & Trabalhos duplicados \\
\hline & E6 & Artigos de magazine \\
\hline & E7 & Artigos com fins publicitários \\
\hline
\end{tabular}

Fonte: Fonte: a autora, adaptado de Oliveira e Gomes (2015)

\section{Questões de pesquisa}

A seleção das fontes buscou responder os seguintes questionamentos:

Q1. Quais os parâmetros para desenvolver um processo de Orientação Profissional com estudantes da Educação Profissional e Tecnológica envolvendo a gamificação e levando em consideração as especificidades dessa modalidade de educação?

Q2. Como a Orientação Profissional tem sido desenvolvida a partir das vertentes psicométrica, sócio-histórica, e quais as outras abordagens em uso atualmente?

Q3. Quais as principais aplicações de uso da gamificação relatadas na literatura? 
No intuito de tornar mais clara a compreensão dos objetivos que embasam as questões levantadas nesta RSL, segue um quadro expositivo comas perguntas e suas respectivas motivações:

Quadro 3 - Artigos selecionados para análise na RSL

\begin{tabular}{|c|c|c|}
\hline ID & Questão - problema & Motivação \\
\hline Q1 & $\begin{array}{l}\text { Quais os parâmetros para desenvolver um } \\
\text { processo de Orientação Profissional com } \\
\text { estudantes da Educação Profissional e } \\
\text { Tecnológica envolvendo a gamificação e } \\
\text { levando em consideração as especificidades } \\
\text { dessa modalidade de educação? }\end{array}$ & 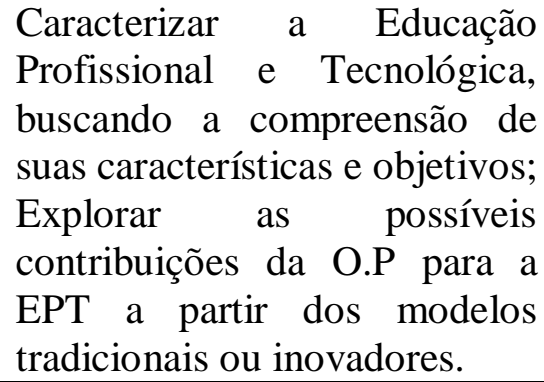 \\
\hline $\mathrm{Q} 2$ & $\begin{array}{l}\text { Como a Orientação Profissional tem sido } \\
\text { desenvolvida a partir das vertentes } \\
\text { psicométrica, sócio-histórica, e quais as outras } \\
\text { abordagens em uso atualmente? }\end{array}$ & $\begin{array}{l}\text { Conceituar e identificar as } \\
\text { configurações da O.P e como } \\
\text { ela tem se desenvolvido até o } \\
\text { momento atual. }\end{array}$ \\
\hline Q3 & $\begin{array}{l}\text { Quais as principais aplicações de uso da } \\
\text { gamificação relatadas na literatura? }\end{array}$ & $\begin{array}{l}\text { Reconhecer os parâmetros, as } \\
\text { características essenciais, as } \\
\text { vantagens e limitações da } \\
\text { gamificação, de modo a } \\
\text { permitir que a ferramenta } \\
\text { possa ser adaptada para o } \\
\text { contexto da O.P; } \\
\text { identificar os contextos e } \\
\text { ambientes em que a } \\
\text { gamificação está sendo } \\
\text { utilizada, através das } \\
\text { publicações disponíveis, } \\
\text { avaliando se existem } \\
\text { experiências de uso na O.P ou } \\
\text { se trata-se de uma inovação na } \\
\text { área. }\end{array}$ \\
\hline
\end{tabular}

\section{Estudos selecionados para análise}

Os estudos foram incluídos na Revisão Sistemática de Literatura (RSL) com o objetivo de auxiliar na compreensão dos questionamentos apontados acima. No Quadro 3 estão expostos os trabalhos selecionados para a RSL: 
ISSN: 2594-4827

Quadro 4 - Artigos selecionados para análise na RSL

\begin{tabular}{|c|c|c|c|c|c|}
\hline ID & Artigos & Periódico & Ano & $\begin{array}{c}\text { Strings } \\
\text { de busca }\end{array}$ & $\begin{array}{c}\text { Critérios } \\
\text { de } \\
\text { Inclusão }\end{array}$ \\
\hline Op 1 & $\begin{array}{l}\text { Desenvolvimento de carreira de } \\
\text { estudantes durante a graduação: } \\
\text { análise de fundamentos } \\
\text { epistemológicos em estudos } \\
\text { nacionais. }\end{array}$ & $\begin{array}{l}\text { Revista Psicologia: } \\
\text { Organizações e } \\
\text { Trabalho }\end{array}$ & 2017 & S1 & $\mathrm{I} 1, \mathrm{I} 2, \mathrm{I} 5$ \\
\hline Gm1 & $\begin{array}{l}\text { A Gamificação como Estratégia } \\
\text { de Capacitação e o Estado de } \\
\text { Flow: um Estudo de Caso em } \\
\text { uma Empresa da Área de } \\
\text { Tecnologia da } \\
\text { Informação (TI) da Região Sul } \\
\text { do Brasil. }\end{array}$ & $\begin{array}{l}\text { SBC-Proceedings } \\
\text { of SBGames 2015/ } \\
\text { XIV SBGames. }\end{array}$ & 2015 & S2 & $\mathrm{I} 1, \mathrm{I} 3, \mathrm{I} 5$ \\
\hline $\mathrm{Gm} 2$ & $\begin{array}{l}\text { Gamificação no Ensino: uma } \\
\text { revisão sistemática da literatura } \\
\text { no cenário brasileiro. }\end{array}$ & $\begin{array}{l}\text { Anais do Simpósio } \\
\text { Hipertexto e } \\
\text { Tecnologias na } \\
\text { Educação, 6., Niterói }\end{array}$ & 2015 & S2 & $\mathrm{I} 1, \mathrm{I} 3, \mathrm{I} 5$ \\
\hline Gm3 & $\begin{array}{l}\text { Jogos educativos na engenharia } \\
\text { de requisitos. }\end{array}$ & $\begin{array}{l}\text { Anais do Fórum de } \\
\text { Educação em } \\
\text { Engenharia de } \\
\text { Software (FEES), } \\
\text { Maringá. }\end{array}$ & 2016 & S2 & $\mathrm{I} 1, \mathrm{I} 3, \mathrm{I} 5$ \\
\hline Gm4 & $\begin{array}{l}\text { Um Mapeamento Sistemático de } \\
\text { Gamificação em Software } \\
\text { Educativo no Contexto da } \\
\text { Comunidade Brasileira de } \\
\text { Informática na Educação. }\end{array}$ & $\begin{array}{l}\text { Anais do } \\
\text { Workshop de Informá } \\
\text { tica na Escola. CBIE- } \\
\text { LACLO 2015. } 21 . \\
\text { Maceió }\end{array}$ & 2015 & S2 & $\mathrm{I} 1, \mathrm{I} 3, \mathrm{I} 5$ \\
\hline Gm5 & $\begin{array}{l}\text { Aplicação de Jogos Adaptativos } \\
\text { na Educação: uma Revisão } \\
\text { Sistemática da Literatura. }\end{array}$ & $\begin{array}{l}\text { Anais do Simpósio } \\
\text { Brasileiro de } \\
\text { Informática na } \\
\text { Educação - SBIE, } \\
\text { 17., Uberlândia. }\end{array}$ & 2016 & S2 & $\mathrm{I} 1, \mathrm{I} 3, \mathrm{I} 5$ \\
\hline Gm6 & $\begin{array}{l}\text { Gamificação como fator } \\
\text { motivacional para diminuição } \\
\text { das taxas de evasão nos MOOC }\end{array}$ & $\begin{array}{l}\text { Anais do Congresso } \\
\text { Regional sobre } \\
\text { Tecnologias da } \\
\text { Educação - Ctrl+e, } \\
\text { Natal. }\end{array}$ & 2016 & S2 & $\mathrm{I} 1, \mathrm{I} 3, \mathrm{I} 5$ \\
\hline Gm7 & $\begin{array}{l}\text { Gamificação e jogos para } \\
\text { metodologia científica: proposta } \\
\text { de jogo de tabuleiro e game. }\end{array}$ & $\begin{array}{l}\text { Anais do SBC-- } \\
\text { Proceedings of } \\
\text { SBGames 2017/ XVI } \\
\text { SBGames, 16., } \\
\text { Curitiba. }\end{array}$ & 2017 & S2 & $\mathrm{I} 1, \mathrm{I} 3, \mathrm{I} 5$ \\
\hline Gm8 & $\begin{array}{l}\text { O uso de gamificação e } \\
\text { dificuldades matemáticas: } \\
\text { possíveis aproximações. }\end{array}$ & $\begin{array}{l}\text { Revista Novas } \\
\text { Tecnologias na } \\
\text { Educação, v. } 15, \text { n. } 1\end{array}$ & 2017 & S2 & $\mathrm{I} 1, \mathrm{I} 3, \mathrm{I} 5$ \\
\hline Gm9 & $\begin{array}{l}\text { O uso de gamificação no ensino: } \\
\text { uma revisão sistemática da } \\
\text { literatura. }\end{array}$ & $\begin{array}{l}\text { Anais do SBC- } \\
\text { Proceedings of } \\
\text { SBGames 2017/ XVI } \\
\text { SBGames, 16., } \\
\text { Curitiba. }\end{array}$ & 2017 & S2 & I1, I3, I5 \\
\hline Gm10 & Gamificação e personalização & Anais do & 2018 & S2 & $\mathrm{I} 1, \mathrm{I} 3, \mathrm{I} 5$ \\
\hline
\end{tabular}


ISSN: $2594-4827$

\begin{tabular}{|l|l|l|l|l|l|}
\hline & para idosos. & $\begin{array}{l}\text { CIET/EnPED 2018 - } \\
\text { Educação e } \\
\text { Tecnologias: } \\
\text { Materiais didáticos e } \\
\text { mediação } \\
\text { tecnológica, 4.,São } \\
\text { Carlos }\end{array}$ & & & \\
\hline Gm11 & $\begin{array}{l}\text { O ensino da Filosofia (com TIC) } \\
\text { no Curso de Direito. }\end{array}$ & $\begin{array}{l}\text { Afluente: revista de } \\
\text { letras e linguística, } \\
\text { Bacabal, v.3, n. 7. }\end{array}$ & 2018 & S2 & I1, I3, I5 \\
\hline Gm12 & $\begin{array}{l}\text { O uso de jogos empresariais } \\
\text { como método de engajamento } \\
\text { em gestão de pessoas em } \\
\text { projetos nas organizações de } \\
\text { estruturas matriciais. }\end{array}$ & $\begin{array}{l}\text { Revista International } \\
\text { Contemporary } \\
\text { Management Review, } \\
\text { v. 1, n. 2. }\end{array}$ & 2018 & S2 & I1, I3, I5 \\
\hline
\end{tabular}

Fonte: Fonte: a autora, adaptado de Oliveira e Gomes (2015)

\section{RESULTADOS E DISCUSSÃO}

$\mathrm{Na}$ análise do material coletado observou-se a inexistência de pesquisas que versem sobre o uso da gamificação para o desenvolvimento de processos de orientação profissional na plataforma consultada. Também não foram localizados trabalhos que contemplem a outros formatos de Orientação Profissional desenvolvidos com o público da Educação Profissional e Tecnológica.

Essa ausência aponta ao mesmo tempo um campo fértil para a pesquisa, com potencial para aplicação na prática educacional ampliada e de inovação tecnológica e, além disso, também dá indicativos de que as pesquisas na área da orientação profissional carecem de maiores esforços para o seu desenvolvimento e atualização.

Durante a fase de análise e extração das informações do material coletado, foi observado que as buscas utilizando o termo "gamificação" apresentaram o maior número de produções compatíveis com os objetivos deste trabalho, doze ao todo.

Já as buscas com o termo "orientação profissional" também apresentaram resultados, contudo, vários trabalhos foram excluídos após análise secundária por empregarem o termo em sentidos diferente do utilizado aqui.

Apenas o trabalho de Zatti et al. (2017) apresentou informações relevantes no âmbito dessa proposta. $\mathrm{O}$ artigo é um estudo exploratório e analisa através da revisão da produção científica nacional na área, os fundamentos epistemológicos que sustentam a chamada "psicologia vocacional", que são as perspectivas do objetivismo, construtivismo e construcionismo social. 
Essas perspectivas influenciam a formatação dos processos de Orientação Profissional desde a postura do orientador e do orientando e o papel que lhes compete na O.P, a utilização ou não de instrumentos como testes psicométricos e métodos clínicos, até a própria caracterização dos objetivos e do recorte temporal dessa orientação, passando do momento específico da escolha de "um curso certo ao qual o sujeito é vocacionado", para um processo que se desenvolve ao longo da vida, como observado nas abordagens desenvolvimentistas. Nesse sentido, esse estudo auxilia na compreensão de como a Orientação Profissional tem sido desenvolvida e quais os seus pressupostos e abordagens em uso atualmente.

$\mathrm{Na}$ busca por estudos envolvendo o tema da gamificação, obtivemos uma vasta produção. Foram identificados vários trabalhos de fontes secundárias, como revisões sistemáticas de literatura (NASCIMENTO et al., 2015; ARAÚJO; SILVA; ARANHA, 2016; COELHO NETO; BLANCO; SILVA, 2017; RESENDE; MESQUITA, 2017; WUNSCH; STODULNY, 2018), revisão integrativa (HENRIQUES; ULBRICHT, 2018) e mapeamento sistemático (PEIXOTO et al., 2015). Também obtivemos estudos primários que apresentaram estudo de caso, relato de experiência e experiência de uso (MACHADO et al., 2015; ARAÚJO et al, 2016; MATTAR et al., 2017), bem como estudos exploratórios (MARTINS; FERNANDES, 2016; HOFFMANN; FONSECA, 2018).

Dito isto, passaremos a discorrer sobre os achados na análise do material capturado na base de pesquisa consultada, com vista a responder a questão da pesquisa que indaga sobre as principais aplicações de uso da gamificação relatadas na literatura dentro do recorte estabelecido aqui.

Machado et al. (2015) apresentam um estudo de caso sobre a experiência da utilização de Gamificação aplicada ao contexto de educação coorporativa em um treinamento empresarial em equipes. Os autores destacam que por essa ferramenta promover maior imersão na experiência chamada de "estado de flow", o que contribui também para um maior aproveitamento na aprendizagem.

Os autores consideram que a gamificação tem grande potencial para se desenvolver na educação formal, haja vista encontrar nesses espaços um público com familiaridade e aprendizagem decorrente da interação com os games. Apontam ainda que a mecânica e a dinâmica do game são dois importantes atributos a serem 
aproveitados na gamificação. A primeira envolve os aspectos que desafiam o jogador e o torna desafiador e estimulante. Já o segundo aspecto envolve as interações do jogador com essas regras, é a reação emocional dessa interação (MACHADO et al, 2015).

Nascimento et al (2015) elaboraram uma revisão sistemática de literatura direcionada a conhecer as aplicações da gamificação no ensino e o público ao qual a atividade está sendo direcionada. O estudo concluiu que no Brasil, no período correspondente à pesquisa (2015), o uso da gamificação teve grande crescimento nos Ambientes Virtuais de Aprendizagem (AVAs). Quanto ao público alvo, a pesquisa indicou que o público é bastante diversificado, tendo sido encontrado na amostra coletada, experiência de gamificação como ensino fundamental, médio e superior, mas em todos permanecem os objetivos de aumentar o interesse, o aprendizado e o engajamento dos estudantes em relação aos conteúdos, entre outros (NASCIMENTO et al, 2015).

O trabalho de Araújo et al (2016) traz a experiência de uso da combinação entre gamificação e softwares educativos para o ensino de engenharia de requisitos e foi desenvolvido a partir da identificação e análise de seis jogos e softwares educacionais para o ensino da disciplina. Os autores apontam que as estratégias de gamificação que foram acrescentadas ao uso dos softwares criam um ambiente envolvente, com desafios, regras, interatividade e feedback que geram reações emocionais, trazendo a experiência e o design de jogo em contexto de não-jogo.

$\mathrm{Na}$ pesquisa de mapeamento sistemático de Peixoto et al. (2015) discute-se sobre a utilização de softwares educativos a partir da produção publicada em eventos científicos nacionais. Os autores pontuam que a fundamentação pedagógica, o conteúdo, a interação e a programação faz com que o software educativo se diferencie dos demais (GOMES; PADOVANI, 2005, apud PEIXOTO et al., 2015) e identificaram os objetivos educacionais citados com mais frequência nessas produções, a saber, engajar motivar, apoiar o ensino, promover interação, estimular o interesse, reforçar a aprendizagem, gerar novos objetivos educacionais, recompensar e prevenir. $\mathrm{O}$ engajamento é, segundo os autores, o objetivo que aparece com maior frequência. Além disso, embora várias das características sejam compartilhadas entre os games comuns e aos de caráter educativo, não se tem ainda um consenso de quais delas precisam estar 
presentes para desenvolver a gamificação em plataformas com finalidade de desenvolver aprendizagem.

Araújo, Silva e Aranha (2016) desenvolveram uma revisão sistemática de literatura sobre a aplicação de jogos adaptativos na educação. Entre os achados da pesquisa, concluíram de que a utilização dos jogos aumenta o interesse dos estudantes em participar das atividades e que a absorção da aprendizagem foi melhor com esse método do que com as formas tradicionais. Contudo, há a necessidade de adaptações para cada público com que se deseja trabalhar, a fim de aproveitar melhor o potencial dessa ferramenta. A pesquisa apontou ainda que o uso dos jogos adaptativos na educação tem sido utilizado, de acordo com a amostra, com maior prevalência no Ensino Fundamental II, que compreende do $6^{\circ}$ ao $9^{\circ}$ ano, mas também está sendo utilizado no Ensino Fundamental I, do $1^{\circ}$ ao $5^{\circ}$ ano, e no Ensino Superior. Não foi identificado na RSL trabalhos sobre uso de gamificação no Ensino Médio e não houve predomínio de disciplinas específicas em a ferramenta é utilizada.

Martins e Fernandes (2016) desenvolveram um estudo exploratório acerca de como a gamificação pode ser utilizada como fator motivacional para a diminuição das taxas de evasão nos cursos do tipo MOOC (Massive Open Online Course). Essa modalidade de educação à distância apresenta uma elevada taxa de evasão e o estudo buscou discutir se a utilização da gamificação poderia contribuir para a motivação e manutenção dos estudantes nesses cursos. Mais uma vez o engajamento promovido pela gamificação foi apontado como um fator relevante a ser considerado e que, neste caso, poderia contribuir para a diminuição do índice de evasão e insucesso, mas destacam que essa estratégia não pode ser vista como único fator a influenciar no êxito ou fracasso nos MOOCs.

Os autores apresentam ainda uma definição de gamificação sintética: "gamificar significa aplicar técnicas e elementos utilizados no desenvolvimento dos jogos digitais, como estética, mecânica e dinâmica, em outros contextos, ou seja, gamificar é planejar e projetar um material incluindo conceitos de jogos" (MARTINS; FERNANDES, 2016, p. 203).

Mattar et al. (2017) desenvolveram o seu trabalho com base no relato da experiência obtida com o uso de gamificação atarvés de jogo de tabuleiro e de um game no ensino da disciplina de metodologia científica. Eles assinalam, entre outros aspectos, 
que é essencial desenvolver a narrativa da gamificação de modo que elementos como enredo, personagens, tensão, desafios, competição, conflitos, colaboração, entre outros possam ser combinados para atingir a finalidade educativa. Também apontam que é essencial definir se o objetivo do jogo é ensinar ou avaliar o conhecimento do aluno ou ainda uma combinação dos dois, pois isso irá influenciar no desenho do jogo. Os pesquisadores apontam ainda que para manter o estado de imersão ou "suspensão voluntária da sensação de ficção" é necessário atenção para atributos como interface, jogabilidade, mecânica, arte e som, mantendo o cuidado para dosá-los adequadamente (MATTAR et al.,2017, p.760).

A revisão sistemática de literatura desenvolvida por Coelho Neto, Blanco e Silva (2017) buscou investigar a existência de estudos com experiências de uso da gamificação para auxiliar sujeitos com dificuldades de aprendizagem em matemática e discalculia. Os autores apontam que apesar do vasto número de trabalhos resultantes nas buscas (2008 trabalhos) e de terem sido utilizadas revistas e bases de dados bastante qualificadas, a grande maioria dos estudos se relacionava ao tema "gamificação" de forma mais abrangente (503 trabalhos), apenas três relacionavam-na com a matemática e nenhuma produção voltada para o uso da estratégia como recurso para lidar com dificuldades de aprendizagem em matemática ou discalculia. Isso ponta para uma importante questão relacionada à educação que está descoberta em relação às pesquisas envolvendo gamificação como forma de auxílio aos estudantes e educadores, mas que certamente merece atenção em pesquisas futuras.

Rezende e Mesquita (2017) desenvolveram uma revisão sistemática de literatura visando identificar como está ocorrendo o uso da gamificação no ensino, procurando identificar como essa estratégia pode contribuir para a melhoria do ensino e da aprendizagem. A pesquisa também resultou com achados que apontam o engajamento e a motivação como os elementos em destaque decorrentes dessa forma de interação e aponta ainda que ela poderá resultar também em uma melhoria da experiência dos envolvidos, permitir a contextualização e problematização de conceitos, facilitar o desenvolvimento de habilidades e de interação entre as pessoas e promover meios para os sujeitos se confrontarem e aprenderem a lidar com sucessos e fracassos.

A pesquisa de revisão integrativa de literatura desenvolvida por Henriques e Ulbricht (2018) insvestigou como a gamificação e a personalização estão sendo 
utilizados para desenvolver meios de tornar a utilização das tecnologias mais acessíveis e facilitar a aprendizagem para o público idoso. As autoras fizeram um achado muito interessante que aponta que alguns elementos da gamificação podem variar ou não agradar, dependendo do público e da faixa etária, neste caso, por exemplo, a investigação apontou que recursos como estabelecimento de ranking poderia não ser agardável aos idosos. Isso aponta para uma questão já assinalada por autores como Araújo, Silva e Aranha (2016) acerca da necessidade de adaptar a gamificação para as características de cada público e abre a reflexão sobre como essa ferramenta atua nas emoções em um público que está em transição para a era digital.

O artigo de Wunsch e Stodulny (2018) trata do uso de ferramentas inovadoras para o ensino de filosofia no curso de Direito. As metodologias apontadas pelas autoras são a Aprendizagem Baseada em Problemas (PBL), a Gamificação e a Flipped Classroom (sala de aula invertida). É interessante a proposta de discutir como essas tecnologias podem contribuir também para a educação de nível superior e outras áreas de conhecimento não relacionadas à tecnologia, assinalada neste caso pelas autoras como de "competências não numéricas e intensamente interpretativa" (WUNSCH; STODULNY, 2018, p. 1). Isso aponta para o caráter extremamente adaptativo das metodologias ativas, com destaque para a gamificação.

O estudo exploratório de Hoffmann e Fonseca (2018) discute a utilização de jogos empresariais como forma de engajar as pessoas em estratégias de capacitação, com vistas a aproveitar o engajamento emocional, a motivação e a participação ativa dos sujeitos direcionando-os para o melhor aproveitamento do treinamento. Sendo observado que mais uma vez a gamificação está sendo relacionada à educação em seus vários contextos e, nesse caso, assim como em Machado et al. (2015), esse recurso é empregado na educação coorporartiva.

Após a exposição dos trabalhos relacionados à orientação profissional e gamificação é possivel constatar que está segunda apresenta uma produção considerável e bastante mutável nos últimos, ao passo que a O.P, por se tratar de uma atividade mais relacionada às areas de Psicologia e Educação, tem sua transformação mais lenta.

A categorização desta produção apresentada acima permite apontar que a maior parte dos trabalhos publicados versa sobre revisões de literatura e relatos de experiência da atualização de gamificação no contexto educacional, com nove dos doze artigos 
pesquisados sobre essa temática. O número se amplia ainda mais se considerarmos os dois trabalhos que tratam da gamificação no contexto da educação coorporativa, em que temos a sua utilização como recurso para treinamentos e capacitações. Temos ainda um trabalho que versa sobre a utilização da gamificação e da personalização de recursos tecnológicos para um público específico.

Na revisão sobre Orientação Profissional, os resultados foram incipientes para permitir enxergar com mais clareza como essa atividade está sendo caracterizada na atualidade, carecendo de uma ampliação no escopo de busca para pesquisas futuras.

Já na busca por informações sobre a Educação Profissional e Tecnológica como não houveram resultados alinhados aos critérios estabelecidos, não é possivel fazer inferências de relação com os demais termos da pesquisa, apontando apenas para indicativos de que não existem relatos de experiências de Orientação Profissional com gamificação nesta modalidade de ensino. Deste modo, compreende-se a necessidade de desenvolver trabalhos futuros com uma pespectiva mais ampliada, de modo a contemplar a bsuca por experiencias de O.P e gamificação em outras instituições que desenvolve a educação profissional, como escolas estaduais profisionalizantes e as instituições que ofertam cursos profissionalizantes e que compõe o sistema $\mathrm{S}$.

\section{CONSIDERAÇÕES FINAIS}

Alguns questionamentos ainda não foram respondidos de forma satisfatória com essa RSL, o que indica a necessidade de ampliar o escopo da pesquisa para outras bases de dados e outros idiomas. Não foram encontrados estudos vinculando a gamificação à Orientação Profissional, o que indica ao mesmo tempo uma área sedenta de pesquisa com potencial para inovação das tecnologias utilizadas em áreas distintas, mas também torna claro a maior dificuldade que será criar parâmetros ou diretrizes que possam aproveitar bem as características da gamificação com vistas a ter o maior envolvimento e motivação do público-alvo, fugindo da perspectiva de uma investigação fria e neutra, desinvestindo o pesquisador do lugar de suposto saber e colocando-o em uma relação mais horizontalizada, face-a-face, destituída de uma hierarquização rígida.

A proposta de combinar a gamificação com a orientação profissional é justamente promover o engajamento dos participantes, sobretudo dos jovens nativos digitais, cujas necessidades e o contexto são também diferenciados daqueles de décadas atrás. Por fim, 
esse trabalho se encerra abrindo ainda mais questionamentos que carecem de investigação teórica e experimentação prática que possam comprovar ou refutar a viabilidade de combinar no processo de Orientação Profissional as estratégias de gamificação e direcioná-la para estudantes da Educação Profissional e Tecnológica.

\section{REFERÊNCIAS}

AMBIEL, Rodolfo Augusto Matteo et al. Avaliação de processos de orientação profissional e de carreira: problemas e possibilidades. Aval. psicol., Itatiba, v. 16, n. 2, p. 128-136, 2017. Disponível em: 〈http://dx.doi.org/10.15689/AP.2017.1602.02〉. Acesso em: 20 ago. 2018.

ANTUNES, Ricardo L.C. Os Sentidos do Trabalho: ensaio sobre a afirmação e a negação do trabalho - $2^{\mathrm{a}}$ Edição, $10^{\mathrm{a}}$ reimpr. rev. e ampl. - São Paulo, SP: Boitempo, 2009.

ARAÚJO, Daniel Negreiros et al. Jogos educativos na engenharia de requisitos. In: Fórum de Educação em Engenharia de Software (FEES), 10., 2016, Maringá. Anais [...]. Maringá: 2016. Disponível em: <http://www.cin.ufpe.br/ jhcp/publica/fees2016.pdf>. Acesso em: 10 out. 2018.

ARAÚJO, Wendell Oliveira de; SILVA, Thiago Reis da; ARANHA, Eduardo H. S. Aplicação de Jogos Adaptativos na Educação: uma Revisão Sistemática da Literatura. In: Simpósio Brasileiro de Informática na Educação - SBIE, 17., 2016, Uberlândia. Anais [...]. Uberlândia: 2016. Disponível em: <https://doi.org/10.5753/cbie.sbie.2016.587>. Acesso em: 10 out. 2018.

COELHO NETO, João; BLANCO, Marília Bazan; SILVA, Juliano Aléssio. O uso de gamificação e dificuldades matemáticas: possíveis aproximações. Revista Novas Tecnologias na Educação, v. 15, n. 1, p. 1-9, 2017. Disponível em: < DOI: https://doi.org/10.22456/1679-1916.75151>. Acesso em: 10 out. 2018.

HENRIQUES, Cecília; ULBRICHT, Vania Ribas. Gamificação e personalização para idosos. In: CIET/EnPED 2018 - Educação e Tecnologias: Materiais didáticos e mediação tecnológica, 4., 2018, São Carlos. Anais [...]. São Carlos: 2018. Disponível em: <http://cietenped.ufscar.br/submissao/index.php/2018/article/view/76>. Acesso em: 10 out. 2018.

HOFFMANN, Guilherme; FONSECA, Ludmilla Lopes da. O uso de jogos empresariais como método de engajamento em gestão de pessoas em projetos nas organizações de estruturas matriciais. Revista International Contemporary Management Review, v. 1, n. 2, p. 1-16, 2018. Disponível em: 〈 http://icmreview.com/icmr/article/view/31〉. Acesso em: 10 out. 2018. 
JORGE, Carlos Francisco Bitencourt; SUTTON, Michael J. D. Games como estratégia na construção e gestão do conhecimento no contexto da inteligência organizacional. Rev. Perspectivas em Gestão e Conhecimento, João Pessoa, v.6, número especial, p.103-118, 2016. Disponível em: 〈http://periodicos.ufpb.br/ojs2/index.php/pgc〉. Acesso em:14 ago. 2018

OLIVEIRA, Francisco Kelsen; GOMES, Alex Sandro. Uma revisão sistemática da literatura sobre ferramentas de autoria de IMS-LD. Anais do XXVI Simpósio Brasileiro de Informática na Educação (SBIE 2015), CBIE-LACLO 2015. Disponível em: <https://doi.org/10.5753/cbie.sbie.2015.376> Acesso em: 14 jan. 2019.

MACHADO, Lisiane et al. A Gamificação como Estratégia de Capacitação e o Estado de Flow: um Estudo de Caso em uma Empresa da Área de Tecnologia da Informação (TI) da Região Sul do Brasil. In: SBC - Proceedings of SBGames 2015/ XIV SBGames. 14, 2015, Teresina. Anais [...]. Teresina: 2015. Acesso em 10 out. 2018. Disponível em <

https://s3.amazonaws.com/academia.edu.documents/40955017/147601.pdf?AWSAcces $\underline{\text { sKeyId}=\text { AKIAIWOWYYGZ2Y53UL3A } \& \text { Expires }=1548729180 \& \text { Signature }=\text { ruVY\% } 2 \mathrm{~F}}$ $\% 2 \mathrm{~B} \% 2 \mathrm{~B} \% 2 \mathrm{Bs} \% 2 \mathrm{Bea} 3 \mathrm{cfsxD} 9 \mathrm{f} 4 \mathrm{ItMLWk} \% 3 \mathrm{D} \&$ response-contentdisposition=inline $\% 3 \mathrm{~B} \% 20$ filename\%3DA Gamificacao como Estrategia de Capacit. pdf>.

MACHADO, Yane Ferreira; OLIVEIRA, Francisco Kelsen. Orientação profissional e Gamificação: uma articulação possível? In: Anais do I Seminário Nacional de Educação Profissional e Tecnológica do IFSul, Charqueadas, 2018. Disponível em $<$ https://doity.com.br/anais/i-seminario-nacional-de-ept/trabalho/72797> Acesso em 19 jun. 2019.

MARTINS, Raiane dos Santos; FERNANDES, Kleber Tavares. Gamificação como fator motivacional para diminuição das taxas de evasão nos MOOC. In: Congresso Regional sobre Tecnologias da Educação - Ctrl+e, 2016, Natal. Anais [...]. Natal: 2016. Acesso em: 10 out. 2018. Disponível em: <http://ceur-ws.org/Vol1667/CtrlE_2016_AC_paper_37.pdf>

MASSI, Maria Lúcia Gili. Criação de objetos de aprendizagem gamificadas para uso em sala de treinamento. Revista Científica Hermes, n.17, p.18-35, 2017. Disponível em: $<$ http://www.fipen.edu.br/hermes1/index.php/hermes1/article/view/304>. Acesso em: 14 ago. 2018.

MATTAR, João et al. Gamificação e jogos para metodologia científica: proposta de jogo de tabuleiro e game. In: SBC - Proceedings of SBGames 2017/ XVI SBGames, 16., Curitiba, 2017. Anais [...]. Curitiba: 2017. Disponível em <https://www.sbgames.org/sbgames2017/papers/CulturaFull/174979.pdf>. Acesso em: 10 out. 2018.

NASCIMENTO, Sloan Pereira do, et al. Gamificação no Ensino: uma revisão sistemática da literatura no cenário brasileiro. In: Simpósio Hipertexto e Tecnologias na Educação, 6., Niterói, 2015. Anais [...]. Niterói: 2015. Disponível em: < 
ISSN: $2594-4827$

http://www.nehte.com.br/simposio/anais/Anais-Hipertexto-

2015/Gamifica\%C3\%A7\%C3\%A3o\%20no\%20Ensino.pdf >. Acesso em: 10 out. 2018.

PEIXOTO, Mariana Maia et al. Um Mapeamento Sistemático de Gamificação em Software Educativo no Contexto da Comunidade Brasileira de Informática na Educação. In: Workshop de Informática na Escola (WIE 2015). CBIELACLO 2015. 21. Maceió, 2015. Anais [...]. Maceió: UFAL, 2015. Disponível em: <https://doi.org/ 10.5753/cbie.wie.2015.584> Acesso em 10 out.2018.

RAMOS, Marise Nogueira. História e Política da Educação Profissional. Curitiba: Instituto Federal do Paraná, 2014. - (Coleção formação pedagógica; v. 5). Disponível em: <http://curitiba.ifpr.edu.br/wp-content/uploads/2016/05/História-e-política-daeducação-profissional.pdf>. Acesso em 10 dez. 2018.

REZENDE, Bruno Amarante Couto; MESQUITA, Vânia dos Santos. O uso de gamificação no ensino: uma revisão sistemática da literatura. In: SBC - Proceedings of SBGames 2017/ XVI SBGames, 16., Curitiba, 2017. Anais [...]. Curitiba: 2017. Disponível em < https://www.sbgames.org/sbgames2017/papers/CulturaShort/175052.pdf>. Acesso em 10 out. 2018 .

SANTOS, Marina Moura; LUNA, Iuri Noves; BARDAGI, Marucia Patta. O desafio da orientação profissional com adolescentes no contexto da modernidade líquida. Revista de Ciências Humanas, v. 48, n. 2, p. 263-281, 2014. Disponível em <http://dx.doi.org/10.5007/2178-4582.2014v48n2p263> Acesso em: 20 ago. 2018.

VIEIRA, Josimar Aparecido; VIEIRA, Marilandi Maria Mascarello. Formação integrada do ensino médio com a educação profissional: o que dizem as pesquisas. Revista Thema, v.13, n.1, p.79-92, 2016. Disponível em: <http://dx.doi.org/10.15536/thema.13.2016.79-92.287> Acesso em: 20 ago. 2018.

WUNSCH, Luana; STODULNY, Luciano. O ensino da Filosofia (com TIC) no Curso de Direito. Afluente: revista de letras e linguística, Bacabal, v.3, n. 7, p. 159-171, 2018. Disponível em: <

http://www.periodicoseletronicos.ufma.br/index.php/afluente/article/view/9160 >. Acesso em: 10 out.2018.

ZATTI, Fernanda; et al . Desenvolvimento de carreira de estudantes durante a graduação: análise de fundamentos epistemológicos em estudos nacionais. Rev. Psicologia: Organizações e Trabalho, Brasília, v. 17, n. 3, p. 150-158, 2017. Disponível em <http://pepsic.bvsalud.org/scielo.php?script=sci arttext\&pid=S198466572017000300003\&lng=pt\&nrm=iso >. Acesso em: 10 out. 2018. 